object to this convention, because it represents one more step away from the actual material, but it can be justified because it provides uniformity and a high level of illustration that is almost always lacking, even in major anatomical works.

The last part of each chapter summarizes functional aspects and the phylogenetic significance of the brains examined. It is here that the authors' scholarship shines most brightly. They present a balanced and comprehensive survey of current knowledge of the particular group of vertebrates described, rather than simply presenting the results of their own research. In rare cases, however, the authors adopt such a neutral position on critical issues that an informed reader will be frustrated.

The third part of this work focuses on brain size in vertebrates, and attempts to recognize major patterns or principles of organization of the major brain divisions. The chapter on brain size beautifully summarizes a vast literature, and the authors rightfully conclude that no single biological factor is likely to account for the vast range of brain sizes among vertebrates. The final chapter, "The Meaning of it All", gives a bird's eye view of the vast range of brain variation that exists among living vertebrates. In so doing, it poses questions that should continue to excite future generations rather than capping the field with a second tombstone.

Glenn Northcutt is in the Department of

Neurosciences, University of California, San Diego, 9500 Gilman Drive, La Jolla, California $92093-$ 0201, USA.

\section{Is meta better?}

\section{How Science Takes Stock: The Story of Meta-Analysis}

by Morton Hunt

Russell Sage Foundation: 1997. Pp. 210. $\$ 29.95, £ 24$

\section{Steve Blinkhorn}

A new kind of alchemy is abroad in the world. Arcane, esoteric and mesmerizing, it promises not to turn base metal into gold, nor to provide an elixir of youth, but to transmute statistical sows' ears into scientific silk purses. Meta-analysis, the systematic synthesis of otherwise inconclusive research findings into hard results, has, in the space of barely two decades, come from a standing start to challenge the blind clinical trial as the principal arbiter of truth and the touchstone of knowledge across a range of biomedical and social sciences.

Precisely because it is in these fields that hard, fast and exact findings are hard to come by, methodology meets morality with peculiar poignancy. Why go to the trouble and expense of blind experimentation, and subject a substantial proportion of a research

\section{Living with the moose}

The North American moose, Alces alces, is the largest living deer, and roams freely across a band of forest covering Newfoundland, the Rocky Mountains, Alaska and as far south as Colorado. If the one on the right seems a little wary, it is perhaps no surprise. Prized by native Americans and an important part of their culture, the moose was hunted by European settlers almost to extinction by the start of this century; the population has since recovered to around a million. Hunting still goes on (but licensed now), and man kills a further 3,500 in road accidents each year. Albert W. Franzmann and Charles C. Schwartz have brought together 21 wildlife researchers to describe the moose's biology and ecology and analyse the strategies of managing and living alongside the animal. The result is the comprehensive Ecology and Management of the North American Moose (Wildlife Management Institute / Smithsonian Institution Press,

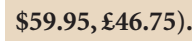

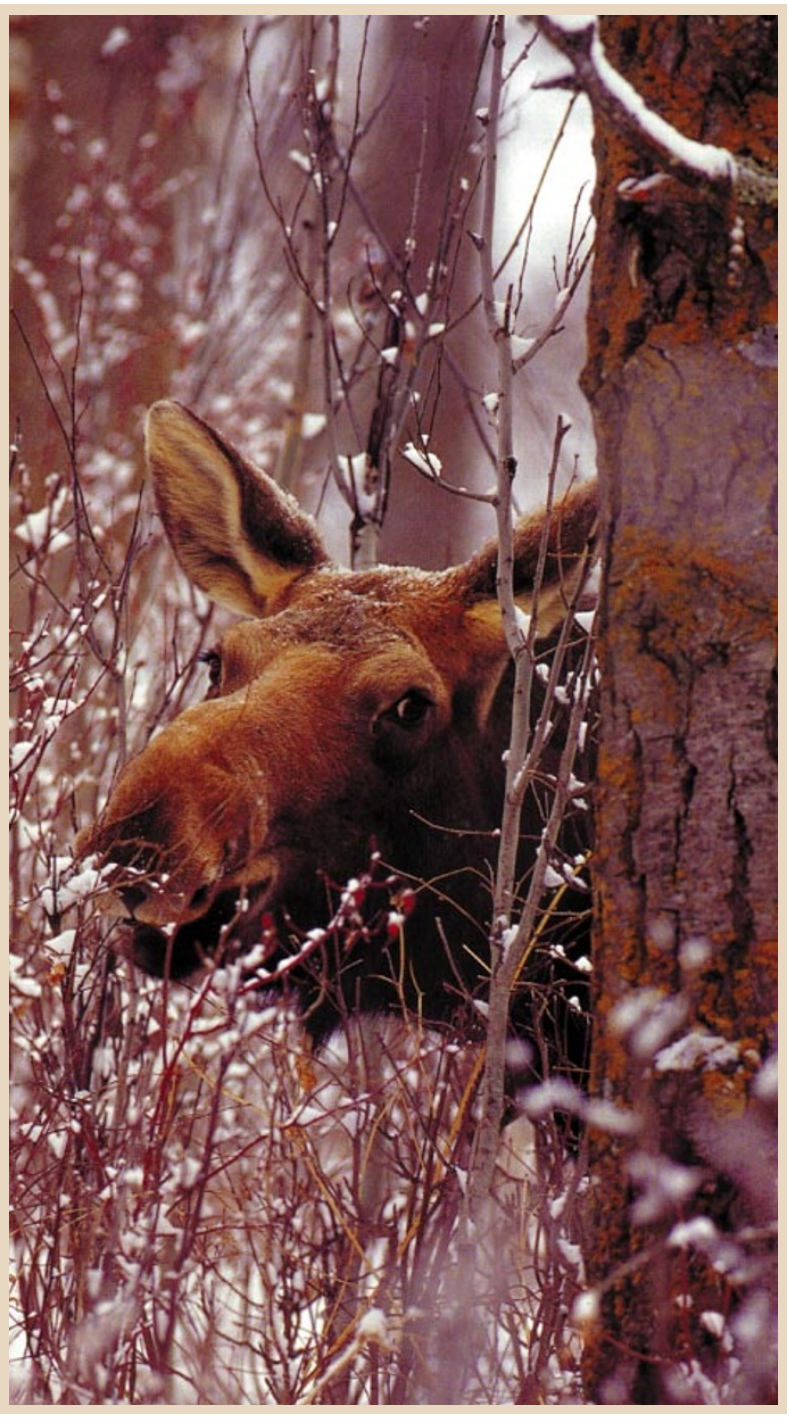

sample to suboptimal treatment, when a little fastidious dredging through inconclusive research literature can be turned, with a little statistical wizardry, into a clear result? The prospect of being able to complete a paper with the words "further research is not necessary" can be too tantalizing to ignore, particularly where conclusions affect the lives and prospects of real people.

The practice of meta-analysis is by no means a soft option. Done properly it requires long and tedious library research to identify studies that meet the criteria for statistical synthesis. In many respects the statistical procedures that form the visible element of meta-analysis are the least troublesome part of the process. The problem for researchers - and journal editors - is that the process of screening suitable results for inclusion in the synthesis is necessarily laborious and painstaking, not to say difficult to replicate. Journal referees can hardly be expected to undertake sufficient checking to ensure that the research literature has thestatus claimed by the meta-analyst. The audience is therefore more than usually reliant on the honesty, accuracy and competence of the research team in evaluating their claims.
An accessible and balanced account of the practice of meta-analysis may be thought overdue. Sadly, this book does not fit the bill. An openly partisan, not to say propagandist, introduction to the field, it has the same cringe-inducing quality found in certain excessively contemporary translations of the New Testament of the Bible.

Morton Hunt has provided subversive footnotes; subversive, that is, of his own purpose. For instance, in a dustjacket puff, Richard Light, one of the leading figures in meta-analysis, tells us that Hunt has "gotten all the important details right". But a footnote in the text tells us that in conventional hypothesis testing " $p$ is the probability that [the] null hypothesis is true". If an understanding of the rudiments of inferential statistics is as unimportant to meta-analysis as this potted travesty of wisdom would suggest, we might as well abandon the pretence that undergraduates can get to grips with conventional hypothesis testing.

A little later in the book, the tale is told of how meta-analysis was first developed to rebut Hans Eysenck's claim that psychotherapy is ineffective. A footnote explains that the British use of the term 'psychotherapy' 
excludes behavioural treatments, whereas the US usage includes them. It appears to have escaped Hunt's attention that Eysenck's argument was precisely that behavioural treatments succeed where 'talk therapies' fail.

It is not only in content that this account disappoints. The prose style owes more than a little to inspirational self-help journalism of a kind to be found in many a glossy monthly. In what, presumably, is intended as an attempt to humanize a dry subject, researchers prowl their offices like caged tigers, have merry twinkles in their eyes and have grandfatherly looks and gentle manners that give no hint of their international eminence. We are invited to believe that the strain of conducting a major metaanalysis together did not affect a couple's marriage, although they divorced a little while after it was finished for Completely Different Reasons. Political correctness has gained not even a toe-hold, for we read of slim, pert women who are 40 years old but look 30 . Research is the more credible, perhaps, when conducted by the pert and neotenous.

Ultimately, the issue raised by metaanalysis concerns the kinds of question science should try to answer. At one extreme there are questions of the kind "Does psychotherapy work?", to which the most likely, if unhelpful, answer is "Probably sometimes, but by no means always". At the other extreme, "Is the mortality associated with lumpectomy greater than that associated with radical mastectomy?" admits a degree of precision. The former question suggests the need to clarify concepts and distinguish circumstances and methods, whereas the latter suggests that a point estimate of a probability is appropriate.

Unfortunately, even when questions are put precisely, the answers provided by meta-analysis do not always concur with the findings of large-scale conventional trials. In a recent review in New England Journal of Medicine, comparison with later randomized trials showed that following the results of meta-analyses would have led to ineffective treatment in $32 \%$ of cases, and the rejection of a useful treatment in 33\% of cases.

In practice, for the foreseeable future, the safest approach is to treat meta-analysis as providing superior guidance in the formulation of hypotheses and the design of conclusive studies, rather than providing conclusive answers itself. It would be a shame to lose the extra leverage it can provide, but this account of its virtues, far from being convincing, serves only to undermine confidence in its usefulness.

Steve Blinkhorn is at Psychometric Research and Development Ltd, Brewnaster House,

The Maltings, St Albans, Hertfordshire AL1 3HT, UK.

\section{Lighting up the dark}

\section{The Quantum Challenge}

by George Greenstein and Arthur G. Zajonc Jones and Bartlett: 1997. Pp. 204. \$50.

\section{Philippe Grangier}

The conceptual foundations of quantum mechanics have been elaborated largely as a result of Gedanken experiments - thought experiments that are physically possible but are not designed to be carried out. Is there anything to learn by implementing a Gedanken experiment? Theoreticists may think not, but George Greenstein and Arthur G. Zajonc say that there is. To support this claim they have taken real experiments as a basis for presenting a detailed analysis of the mysteries of quantum mechanics.

The initial chapters of the book discuss experiments that are now more than ten years old, and the subjects are mature enough to be analysed with great clarity. They include wave-particle duality, illustrated through single-photon and delayedchoice interference experiments, and the uncertainty principle, associated with squeezed light. Special attention is devoted to entangled states and the EinsteinPodolsky-Rosen argument, accompanied by a convincing presentation of the experimental tests of Bell's inequalities.

The final chapters, dealing with measurement and decoherence and dissecting Schrödinger's cat, seem less polished, perhaps because direct experimental evidence was scarce when the book was written. But they nevertheless provide an interesting account of the slow evolution of experimental realization, and help one to appreciate the objectives and subtleties of the achievements that followed.

The book could be read with great profit by students who, after a term of a course on quantum mechanics, have grasped the basic calculatory techniques. A lot can be learnt about what practical quantum mechanics really is from the explanation and contemplation of elegant and subtle experiments.

The conceptual difficulties, carefully listed by the authors, have often been considered as "the dark side of quantum mechanics" and have been hidden away in standard textbooks. In that respect, the great intellectual honesty of the authors, who never hide the difficulties but also never overstate them, will be of great help to young readers. More knowledgeable readers will also learn a lot, but those looking for foggy philosophical arguments may be disappointed. The picture of quantum mechanics that emerges is far from obvious, but it is drawn from the weight of experimental reality.

Philippe Grangier is at the Institut d'Optique, BP 147, F-91403 Orsay cedex, France.

\section{New in paperback}

The Origins of Virtue: Human Instincts and the Evolution of Cooperation

by Matt Ridley

Penguin, £8.99, \$13.95

"The book is extremely well written with the sort of anecdotal detail and with that make for lively reading even when the most abstract topics are being treated", Frans B. M. de Waal, Nature 383, 785 (1996).

\section{Himself and Other Animals: A Portrait of Gerald Durrell}

by David Hughes

Pimlico, £7.99

Candid memoir of the famous conservationist by his friend and publisher of over 40 years.

\section{Unravelling DNA: The Most Important Molecule}

by Maxim D. Frank-Kamenetskii

Addison-Wesley, $\$ 15$

Reviewed by David Lilley in Nature 367, 330 (1994).

\section{The Synaptic Organization of the} Brain, 4th edn

edited by Gordon M. Shepherd

Oxford University Press, $\$ 45$

\section{A Man on the Moon: The Voyages of the Apollo Astronauts}

by Andrew Chaiken

Penguin, $\$ 15.95$

\section{The History of Pain}

by Roselyne Rey

Harvard University Press, $\$ 18.95$, $£ 12.50$

Cultural history. Reviewed by Lucy Bending in Nature 379, 129 (1995).

\section{The Evolutionary Synthesis:} Perspectives on the Unification of Biology

edited by Ernst Mayr and William B. Provine Harvard University Press, $\$ 19.95$, £13.50 Classic essays by key players in the 'modern synthesis' of evolutionary biology.

\section{Albert Einstein and the Frontiers of Physics}

by Jeremy Bernstein

Oxford University Press, £7.99

Biography for beginners.

\section{Prisons of Light: Black Holes}

by Kitty Ferguson

Cambridge University Press, $£ 15.95, \$ 24.95$

Popular introduction.

\section{The Cells of the Body: A History of} Somatic Cell Genetics

by Henry Harris

Cold Spring Harbor Laboratory Press, \$29 